DEVELOPING RESEARCH AND PRACTICE

\title{
Improving the quality of health care for chronic conditions
}

\author{
J E Epping-Jordan, S D Pruitt, R Bengoa, E H Wagner
}

See editorial commentary, p 246

Qual Saf Health Care 2004;13:299-305. doi: 10.1136/qshc.2004.010744

Chronic conditions are increasingly the primary concern of healthcare systems throughout the world. In response to this challenge, the World Health Organization has joined with the MacColl Institute for Healthcare Innovation to adapt the Chronic Care Model (CCM) from a global perspective. The resultant effort is the Innovative Care for Chronic Conditions (ICCC) framework which expands community and policy aspects of improving health care for chronic conditions and includes components at the micro (patient and family), meso (healthcare organisation and community), and macro (policy) levels. The framework provides a flexible but comprehensive base on which to build or redesign health systems in accordance with local resources and demands.

See end of article for authors' affiliations

Correspondence to: J Epping-Jordan, Coordinator, Health Care for Chronic Conditions (CCH), Noncommunicable Diseases and Mental Health (NMH), World

Health Organization, 20

Avenue Appia, $\mathrm{CH}-1211$

Geneva 27, Switzerland: eppingj@who.int

Accepted for publication 22 May 2004 of Botswana's population over the age of 15 years now use tobacco products ${ }^{7}$ and the government has already noted an increase in cancer, diabetes, and hypertension. ${ }^{8}$

Concomitant with this upsurge, around the world many people with chronic conditions are failing to receive appropriate care. This failure of care is due to both quality and access issues and is experienced, often to the greatest extent, by disadvantaged subgroups of the general population. ${ }^{9}$ A recent survey was undertaken of 4000 "sicker adults" in five countries (Australia, Canada, New Zealand, UK, and USA). The sample included people who rated their health as fair or poor; who reported recent serious illness, injury, or disability; or who had recently undergone major surgery or been hospitalised for illness. The results revealed that $33-49 \%$ of respondents were not given advice on health risk behaviours and $47-67 \%$ were not asked for their ideas or opinions about treatment. ${ }^{10}$ In the USA approximately $40 \%$ do not receive adequate health care once a chronic condition becomes apparent. Of the care that is provided, $20 \%$ is deemed clinically inappropriate. ${ }^{11}$ Similar quality concerns have surfaced in the mental health arena where less than $15 \%$ of patients with chronic problems such as major depression, panic disorder, or generalised anxiety disorder receive evidence based treatment. ${ }^{12}$

The quality of health care for chronic conditions in developing countries is at least as concerning and, in many countries, the quality of care is much worse. Developing countries often struggle with the complexity of insufficient resources combined with inadequate access to necessary drugs and technologies. Worldwide, only $5 \%$ of those in need have access to essential HIV/AIDS health care; in Africa, where HIV/AIDS is the leading cause of mortality, this figure drops to $1 \% .{ }^{1}$ In the Caribbean a medical record review of over 1600 patients attending healthcare clinics for diabetes indicated that $50 \%$ had poor blood glucose control. Moreover, over a 12 month period less than one third had received dietary advice and only 5\% had received exercise advice. ${ }^{13}$ Similar findings have been reported in South Africa ${ }^{14}$ and India. ${ }^{15}$

Creative solutions are necessary to address the escalating healthcare demands of chronic conditions, especially in countries with a limited or stressed primary care infrastructure. Across the spectrum of communicable and non-communicable diseases, all chronic conditions place similar demands on health systems, patients and families, and comparable ways of organising health care are similarly effective regardless of biomedical aetiology. Integrated healthcare models that transcend specific illnesses and promote 
patient centred care provide a feasible solution. The inclusion of evidence based approaches can bring increased coherence and efficiency to healthcare systems and provide a means for improving quality across a range of chronic health problems.

To address the quality of healthcare services for chronic conditions, this paper summarises the Chronic Care Model (CCM) and its adaptation for international contexts-the Innovative Care for Chronic Conditions (ICCC) framework.

\section{CHRONIC CARE MODEL (CCM)}

The CCM is an evidence based, conceptual framework developed by one of the authors (EHW) and his colleagues. ${ }^{16}$ The model describes changes to the healthcare system that help practices-particularly those in primary care settingsto improve outcomes among patients with chronic illness. The system changes support the development of informed activated patients and prepared proactive healthcare teams whose interactions become more productive and satisfying around chronic illness (fig 1).

The CCM has guided a number of American healthcare organisations to improve their efforts in care for chronic illness. To date over 1000 healthcare organisations, including approximately 500 community health centres supported by the Health Resources Services Association's Bureau of Primary Health Care, have participated in healthcare improvement activities using the CCM framework. ${ }^{17}$ Most of these organisations have made measurable improvements in the quality of their care. A recent review of the literature reiterates that the most successful chronic disease improvement strategies are consistent with concepts and components identified in the CCM. ${ }^{18}$

The CCM describes the interacting system components which are important for providing good chronic illness care. It comprises four components:

- self-management support;

- delivery system design;

- decision support;

- clinical information systems.

\section{Self-management support}

Providing information and support to enable patients (and families) to care better for their illness, self-management support is central to improving care and outcomes. ${ }^{19}$ Successful self-management support can be effectively delivered in "stand alone" programmes, ${ }^{20-22}$ but recent evidence suggests that long term benefits may require an ongoing collaborative process between patients and professionals. ${ }^{23}$

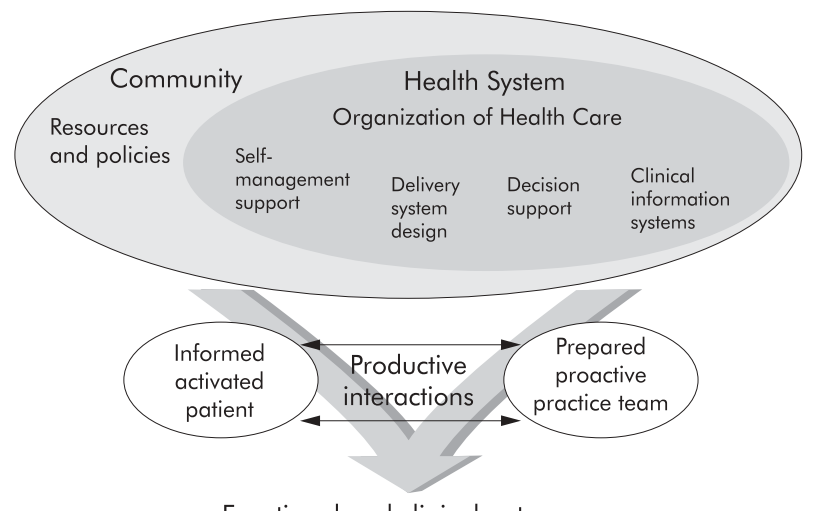

Functional and clinical outcomes

Figure 1 The Chronic Care Model (CCM).

\section{Delivery system design}

Usual healthcare systems oriented to address acute illness make it difficult for productive interactions to occur. An Institute of Medicine report ${ }^{25}$ makes clear that adding greater expectations or simple solutions to systems designed for a different set of healthcare problems is unlikely to be successful. The system must change, and this is reflected in delivery system design. For example, productive interactions are made more likely by planning visits or other interactions in advance. Non-physician members of a practice team are crucial to effective chronic illness care, but they need clear complementary roles. Patients with more complex conditions and/or care needs often benefit from more intensive care from nurse care managers and outreach workers who provide close follow up and help to increase adherence. ${ }^{26}$

\section{Decision support}

Healthcare providers must have access to the expertise necessary to care for patients-decision support in the CCM. Evidence based practice guidelines or protocols ensure that provider teams are aware of effective treatments, but this information must be integrated into the fabric of decision making-for example, reminders or standing orders-to have a meaningful impact on patient care. In addition to guidelines, practice teams must have access to professionals with clinical expertise and experience in the care of the condition. In developed countries these are often medical specialists but might be other types of providers in developing countries.

\section{Clinical information systems}

Clinical information systems provide timely useful data about individual patients and populations of patients. Whether computerised or hand written, information systems are critical for effective chronic condition programmes and an essential feature of those programmes that employ population based strategies such as outreach or directly observed therapy. A disease registry or database that includes information about the process and results of care for all patients is the essential ingredient. Healthcare teams with access to a registry can contact patients with specific needs, deliver planned care, receive feedback on their team's performance, and benefit from reminder systems.

The top part of the CCM pertains to the influence of the larger healthcare system-health care organisation-and of the community in which patients reside-community resources and policies on the effectiveness of chronic illness care. The CCM recognises that improvement in the care of patients with chronic illness will only occur if system leaders, whether private or governmental, make it a priority and provide the leadership, incentives, and resources necessary to make improvements happen. Yet, ironically, a primary limiting factor to a general adoption of the CCM in the USA is the overall fragmentation of health services and the lack of clear policy directions for the management of chronic conditions..$^{27}{ }^{28}$ So, while many healthcare organisations have implemented aspects of the CCM,${ }^{17}$ these changes have not extended to the wider population due to the lack of broader based political, financial, and community support.

\section{INTERNATIONAL ADAPTATION OF THE CCM: THE INNOVATIVE CARE FOR CHRONIC CONDITIONS (ICCC) FRAMEWORK}

The World Health Organization (WHO) considered various programme options in response to the growing prevalence of chronic conditions and the ensuing need to help countries transform their healthcare systems. A first step was to examine the relevance and applicability of the CCM for developing countries. WHO convened a group of health 
leaders from a number of countries in Africa, Asia, Eastern Europe, and Latin America to review the CCM from their countries' perspectives. They agreed that the CCM, if adapted, could serve as a basis for policy development and system redesign. The group then revised and enlarged the CCM.

The resultant effort is the Innovative Care for Chronic Conditions (ICCC) framework (fig 2) which is fully described in a recent WHO publication. ${ }^{29}$ The construction of the framework includes components at the micro (patient and family), meso (healthcare organisation and community), and macro (policy) levels. While the framework does not prescribe specific changes which must be tailored to unique needs and resources, it highlights the need for comprehensive system design or change-the requirements for effective care.

What's new in the ICCC framework? While conceptually linked to the CCM, the ICCC framework reflects the context of international health care and, as such, it places emphasis on different aspects of good care for chronic conditions.

\section{Micro level: the CCM dyad becomes an ICCC triad}

The focal point of the CCM is productive interactions between informed activated patients and prepared proactive practice teams (fig 1). The ICCC framework extends this dyad to a triad through the inclusion of community partners (fig 2) to emphasise the critical role that community leaders and caregivers play in many places. Representing the "micro" or patient interaction level, the triad is a partnership between patients and families, healthcare teams, and community partners. It functions best when every member of the triad is informed, motivated, and prepared with the skills necessary to manage chronic conditions. Each member of the triad communicates and collaborates with the others in the triad. The larger healthcare organisation, the broader community, and the policy environment influence and support the patient-team-community triad.

Another change at the micro level is the transformation of the terms "informed and activated" patients in the CCM to the terms "informed, motivated, and prepared" patients in the ICCC framework. This change was made to underscore the reality that, in many developing country contexts, it is insufficient to be merely "activated". One must also have access to the necessary medications and medical equipment, self-monitoring tools, and self-management skills. The term "prepared" was chosen to reflect these broad needs.

One good example of the triad can be found in rural Haiti, one of the poorest countries in the world. Patients with HIV/

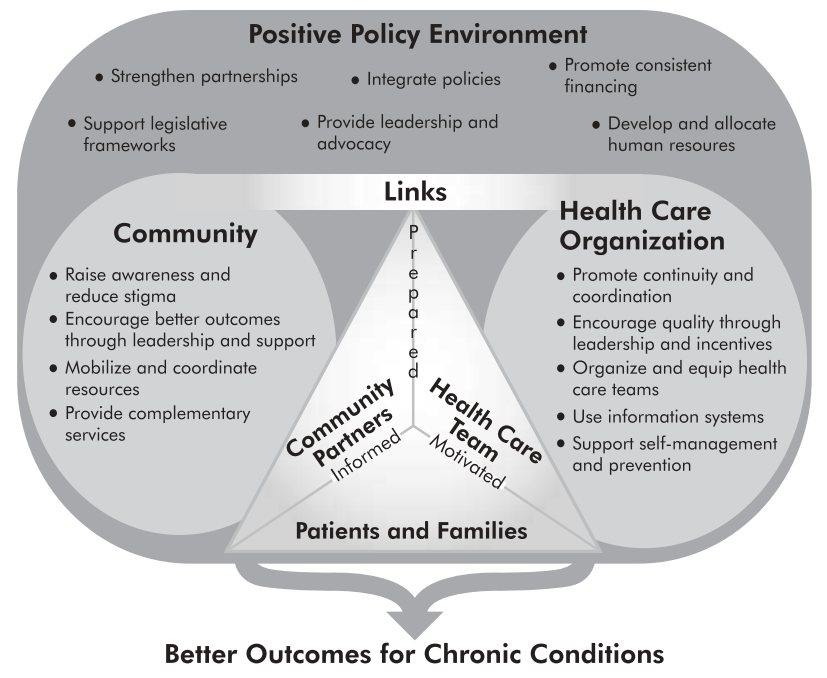

Figure 2 The Innovative Care for Chronic Conditions (ICCC) framework.
AIDS are provided with self-management support and community based follow up. Each patient has a treatment buddy, often a community health worker, who observes ingestion of pills, responds to concerns of patients and families, and provides support in the community. Among a cohort of 60 patients, primarily peasant farmers, side effects have been rare and readily managed. ${ }^{30}$

\section{Meso level: the healthcare organisation remains essential but the community assumes prominence}

Healthcare organisation aspects of the ICCC framework at the meso level are closely related to components in the CCM but are reframed to reflect the realities of less developed health care. For example, the framework calls for "organised and well equipped" healthcare teams rather than for "decision support". Policymakers who commented upon draft versions of the framework made this distinction and noted that decision support tools are necessary but insufficient in many developing country settings where examination supplies, diagnostic tests, and medications are frequently in short supply. They felt it was more appropriate to speak of "equipping" teams which could encompass guidelines, decision support tools, and also essential supplies and technologies. Another distinction between the healthcare organisation aspects of the CCM and the ICCC framework is the latter's strong emphasis on continuity and coordination of services. This is due to a frequent and significant problem in developing countries with coordination between local primary health services and more specialised providers based in cities and hospitals.

The community is strongly emphasised in the ICCC framework as supporting organised health care by echoing essential messages about prevention and management of chronic problems. This emphasis in the framework is meant to reflect the significant roles of communities in developing countries concerning health related issues. In all countries the lives of patients with chronic problems extend far beyond the walls of formal clinics and the reach of healthcare teams. Moreover, communities can provide services that complement and support the care provided in healthcare organisations; they can bridge the service gap between the organised clinical care and the real world of patients and their families. ${ }^{31}{ }^{32}$ In Zambia, for example, teams of mobile community nurses provide home care for patients with TB and HIV/AIDS. These nurses support community health workers and community volunteers in providing selfmanagement support to patients and support to family caregivers. $^{33}$

\section{Macro level: policies and financing become the system driver}

In most parts of the world a positive policy environment that supports care for chronic conditions is essential to reduce the burden of these long term health problems. Legislation, leadership, policy integration, partnerships, financing, and allocation of human resources are examples of policy activities that occur at the macro level and are depicted in the ICCC framework.

\section{Provide leadership and advocacy}

Senior political leaders can have a considerable influence in improving health care for chronic conditions. Lower level policymakers, patients, communities, and healthcare providers can greatly influence these leaders to persuade them to create the right conditions for a positive policy environment. Policymakers can also increase awareness by using a range of strategies. All forms of media can be used as a powerful forum for educating the public, promoting new attitudes, and providing them with the needed skills for improving their health status. South Africa's "Soul City", for example, uses 
drama and entertainment to reach more than 16 million South Africans on a range of health related issues including HIV/AIDS, depression, and asthma. Each Soul City series includes 13 episodes of a prime time television show, a daily radio drama, and an advertising campaign that keeps people talking about the issues. The programme has been running over 10 years and its audience size continues to grow, now expanding across a range of countries and continents. ${ }^{34}$

\section{Integrate policies}

Integrated policies for chronic conditions minimise redundancies and fragmentation in the healthcare system. Policies are most effective when they blur boundaries among specific diseases and when they emphasise management of defined populations of patients over management of a single patient. They must be integrated across traditionally disparate disease categories such as HIV/AIDS and diabetes, as well as levels of care and care settings such as primary health care and hospital based care. Policies may be more successful when they encompass prevention, promotion, and control strategies, and when they make explicit links to other governmental programmes and community based organisations.

Two countries that have successfully integrated aspects of their policies for chronic conditions are India and the Philippines. In India the federal government has adopted an integrated non-communicable disease programme that includes health education for prevention, standardised treatment protocols, rehabilitation for people with disabilities, and research support. ${ }^{35}$ The Philippines has integrated aspects of prevention and control of diabetes including the establishment of coordinated health systems that involve clinicians, researchers, allied health professionals, community based health workers, and lay volunteers. ${ }^{36}$

\section{Promote consistent financing}

The effective control of chronic conditions requires long term investments in the infrastructure for care. Financing decisions based on principles of equity and effectiveness will help assure the most beneficial allocation of scarce resources. All financing components (funding, resource allocation, contracting, and reimbursement) should be used as a means for encouraging the implementation of innovative healthcare strategies. Costa Rica, for example, uses contracting combined with performance indicators to increase the quality and coherence of its primary healthcare services. ${ }^{37}$

\section{Develop and allocate human resources}

Effective care for chronic conditions cannot take place unless there are well trained health professionals to assure appropriate use of medications and other modalities. In addition to pharmacotherapy, courses covering the role of behaviour in health and illness must become standard curricula for all healthcare education. Students also should learn basic principles of screening, brief intervention, and facilitating behaviour change in their patients. If not already in place, policymakers need to develop requirements for postgraduate continuing education and establish systems to disseminate research findings and other relevant information to providers.

The concept of allocation and development of human resources extends beyond direct service providers. Policy and service planners, researchers, information technology designers, and support personnel are necessary to improve care for chronic problems. Exploring new categories of healthcare workers such as self-management counsellors will be worthwhile as they can assist in meeting the growing demands of care for chronic conditions.

In South Africa a nurse led non-communicable disease primary health care programme was established for hypertension, diabetes, asthma, and epilepsy. Using a comprehensive care approach, nurses were able to achieve good disease control among most of the patient population $(68 \%$ of patients with hypertension, $82 \%$ of those with diabetes, and $84 \%$ of those with asthma). These results indicate that appropriate chronic disease management can be achieved in resource poor settings by optimising existing human resources. ${ }^{38}$

\section{Support legislative frameworks}

Legislation and regulations can reduce the burden of chronic conditions. Controls on health threatening products such as tobacco and alcohol also reduce the burden associated with chronic conditions. Age eligibility laws, excise taxes, and local statutes that restrict sales to youth are effective, as are laws that limit or ban tobacco and alcohol advertising. The WHO's Framework Convention on Tobacco Control (FCTC), for example, requires countries to impose restrictions on tobacco advertising, sponsorship and promotion, establish new labelling and clean indoor air controls, strengthen legislation to reduce tobacco smuggling, and provide clinical interventions to promote tobacco cessation. ${ }^{39}$

Policymakers can also influence the quality of health care through legislation, regulation, accreditation, minimum standards, and monitoring; and they can allocate the needed resources to ensure the achievement of quality standards. Organised national strategies for quality improvement bring potent tools and attention to optimal functioning of all levels of the healthcare system. Finally, legislation can protect the rights of people with chronic conditions. The promotion of human rights occurs in part through access to health care and voluntary treatment. Regulatory frameworks can be developed and enforced that protect healthcare institutions and workers. Anti-discrimination laws for housing and employing persons with chronic conditions can also be adopted.

\section{Strengthen partnerships}

Because patients with chronic conditions will spend most of their lives outside formal healthcare settings, it is essential for health policymakers to develop and coordinate intersectoral partnerships with other governmental sectors, the private health sector, and community groups and organisations. Israel's community based Yad Sarah programme, ${ }^{40}$ which provides wheelchairs and home based care to people in need, is one example of a fruitful relationship between private charities and public health sectors.

Policymakers also have an important role to play in supporting the development of community groups and nongovernmental organisations. They can ensure that these organisations play a fundamental role in policymaking and planning of health services. Connections with district, municipal, or local governments and employers will benefit from close examination and strengthening where necessary.

\section{Public health is related to the management of chronic conditions}

Healthcare managers often feel the strain of deciding whether to invest in health care or broader public health initiatives. The former focuses on clinical prevention and treatment and the latter on broader health promotion and disease prevention interventions in the community. The ICCC framework tries to address this tension by showing the complementary nature of working across the disease continuum (fig 3) in a comprehensive way. This is particularly important for chronic conditions because both upstream public health interventions for the general population and downstream organised management of chronic conditions within healthcare services are required. WHO supports the need to intervene across the continuum to achieve impact on a chronic condition in a community. Either intervening 


\begin{tabular}{|c|c|c|c|c|c|}
\hline $\begin{array}{l}\text { General } \\
\text { population }\end{array}$ & $\begin{array}{l}\text { At risk } \\
\text { overweight } \\
\text { or obese }\end{array}$ & $\begin{array}{l}\text { At risk impaired } \\
\text { glucose } \\
\text { balance }\end{array}$ & $\begin{array}{l}\text { Undiagnosed } \\
\text { diabetes }\end{array}$ & $\begin{array}{l}\text { Diagnosed } \\
\text { diabetes }\end{array}$ & $\begin{array}{l}\text { Diabetes } \\
\text { complications }\end{array}$ \\
\hline \multicolumn{4}{|c|}{ Without diabetes } & With diabete & \\
\hline
\end{tabular}

Figure 3 The disease continuum as applied to one chronic condition (diabetes).

upstream or intervening downstream exclusively will probably not achieve comprehensive control of a chronic condition in a community. This argument is even more important today because of convincing evidence of positive health outcomes using interventions across the disease continuum.

Fortunately there has been a revival in "whole systems" thinking and a renewed commitment to the value of partnerships and integrated health care. The ICCC framework reflects this revival by providing a framework that helps to repair the fragmentation of health services and provides an opportunity to link to broader population interventions.

\section{INTERNATIONAL EXPERIENCES WITH THE CCM AND ICCC FRAMEWORK}

Increasingly, the CCM and ICCC framework are being implemented around the world. Some implementation is occurring at the grass roots level in response to local needs, whereas other system redesign is the result of top level political commitment to improve health care for chronic conditions.

\section{Canada}

A group from the Vancouver Island Health Authority and James Bay Community Project in British Columbia, Canada have been integrating principles of population health promotion with the CCM. Their result is the Expanded Chronic Care Model, which-similar to the ICCC framework-expands community and policy aspects of the CCM but retains its original healthcare organisation components. ${ }^{41}$ This model provides a viable alternative to the ICCC framework for those interested in expanding the policy components of care while preserving the original structure of the CCM.

\section{Mexico}

A diabetes quality improvement effort, using the CCM as the basis for change, is underway in the state of Veracruz. Ten health centres (with two to four physicians each) are participating-five in the intervention group and five providing usual care. Clinical outcomes will be measured to evaluate the success of the programme.

\section{Morocco}

The ICCC framework served as the conceptual basis for a health care for chronic conditions situation analysis for the Government of Morocco. The building blocks of the framework initially were operationalised and then used to evaluate the current system of care. Strengths, gaps, and areas for reinforcement were identified through this strategy. Based on the analysis, a report was delivered to the Government of Morocco with recommendations for action.

\section{Russian Federation}

The Russian Federation's Central Public Health Research Institute in the Ministry of Health has recently launched a project to adapt quality improvement methodology to the Russian healthcare system; a total of 56 healthcare teams from 23 oblasts are participating in this improvement work. The ICCC framework is being used as the conceptual basis for developing changes for the secondary prevention of cerebrovascular disease complications due to ischemic heart disease, diabetes, hypertension, and hyperlipidemia.

\section{Rwanda}

The ICCC framework is being used to design a system of care for HIV/AIDS. The healthcare teams convened initially in June 2003. Using the ICCC framework as their road map, the aim of the Ministry of Health is that the estimated 500000 people living with HIV/AIDS in this country will be receiving comprehensive treatment by 2005.

\section{United Kingdom}

In the UK the National Health Service (NHS) is midway through a 10 year quality care agenda. Progress to date reveals a number of improvements in care, but additional work is necessary to reach 2010 targets. ${ }^{42}$ One strategy to help the NHS realise its quality goals is to improve the management of chronic conditions and the CCM has recently been suggested as a generic chronic disease model that could help with this. ${ }^{43}$

Most of these implementation experiences are being accompanied by operational research evaluations. This essential information will be used to refine the ICCC framework further and to implement it across different country contexts. We also anticipate that these experiences will serve as a catalyst for change at a global level. Just as individual patients, clinicians, and healthcare organisations can assume "change agent" status for others, so can countries. In a few years, as these projects move from implementation to results, representatives from countries that have experienced improvement will be able to speak from positions of authority about the benefits of change. Just as patients tend to heed the advice of those in similar situations, policymakers are inclined to listen to their colleagues who they perceive to be "people like me".

To complete all pieces of the improvement puzzle, it is essential for those in positions of authority to empower consumers to be able to recognise and demand high quality health care for chronic conditions.$^{44}$ Research has shown that providers' clinical practice patterns are substantially influenced by patients' requests. ${ }^{45}$ This research implies that strategically positioned healthcare campaigns, directed at consumers of health care, could empower them to become active participants in their health care and, indeed, to serve as a complementary force for improving the type and quality of care that they receive.

\section{CONCLUSIONS}

Today's healthcare leaders can no longer remain passive in the face of changing disease burden and rising demands and must actively work to determine effective strategies to address the growing problem of chronic conditions. Although the task may seem overwhelming, they have a full range of tools at their disposal that can shape the delivery and structure of health care for long term problems. Equipped with properly formulated tools, healthcare leaders can make the necessary and sustainable impact on the health of the populations for which they are responsible. 


\section{Key messages}

- Around the world the burden of chronic conditions is increasing dramatically.

- Most health systems are not equipped to meet these shiffing health care needs.

- Growing evidence from around the world suggests that patients with chronic conditions do better when they receive effective treatment within an integrated system with self-management support and regular follow up.

- Evidence also suggests that organized systems of care, not just individual healthcare workers, are essential in producing positive outcomes.

- Incorporating these principles, the Chronic Care Model (CCM) has successfully changed healthcare practices for chronic conditions in a range of American systems.

- The World Health Organization has joined with the MacColl Institute for Healthcare Innovation to adapt the CCM from a global perspective.

- The resultant model, the Innovative Care for Chronic Conditions (ICCC) framework, depicts the complementary nature of working across the disease continuum in a comprehensive way, and emphasizes community and policy aspects of improving care.

- The CCM and ICCC framework are now being disseminated, implemented and evaluated in healthcare systems around the world.

The CCM and its extension, the ICCC framework, are two tools for generating essential improvements in the health and delivery of health care in countries throughout the world. The CCM has successfully changed healthcare practices for chronic conditions in a variety of American systems, highlighting the importance of self-management, delivery systems designed around long term problems, evidence based decision support for providers, and clinical information systems. The CCM stresses the need for the community and healthcare system to combine efforts to produce informed and activated patients who interact with prepared and proactive healthcare teams.

In expanding the CCM to address care for chronic conditions on the international front, the ICCC framework depicts the complementary nature of working across the disease continuum in a comprehensive way. In the ICCC framework the positive policy environment surrounds and supports community efforts that are formally connected to healthcare organisations. These entities, in turn, support patients and families, community partners, and care teams that are informed, motivated, and prepared to manage chronic conditions.

Chronic conditions are increasingly becoming the primary concern of healthcare systems throughout the world and are soon to be the leading cause of disability. However, the future is not bleak if healthcare leaders in developed and developing countries alike face the challenge of chronic conditions. The CCM and the ICCC framework can guide the way for action.

\section{Authors' affiliations \\ J E Epping-Jordan, R Bengoa, World Health Organization, Geneva, Switzerland \\ S D Pruitt, Kaiser Permanente, Sacramento, CA, USA}

E H Wagner, MacColl Institute for Healthcare Innovation, Seattle, WA, USA
This paper presents the views of its authors and does not necessarily represent the decisions or the stated policy of the World Health Organization.

\section{REFERENCES}

1 World Health Organization. The World Health Report 2003: Shaping the future. Geneva: World Health Organization, 2003.

2 Murray C, Lopez A. The global burden of disease: a comprehensive assessment of mortality and disability from disease, injuries and risk factors in 1990 and projected to 2020. Boston, MA: Harvard University Press, 1996.

3 World Health Organization. Current and future long-term needs. Geneva: World Health Organization, 2002.

4 Kitihata MM, Tegger MK, Wagner EH, et al. Comprehensive health care for people infected with HIV in developing countries. BMJ 2002;325:954-7.

5 Setel P, Saker L, Unwin NC, et al. Is it time to reassess the categorization of disease burdens in low-income countries? Am J Public Health 2004;94:384-8.

6 UNAIDS. Report on the global HIV/AIDS epidemic 2002. Geneva: UNAIDS, 2002.

7 Corrao MA, Guindon GE, Sharma N, et al. Tobacco control country profiles. Atlanta: American Cancer Society, 2000.

8 Botswana Ministry of Health, Community Health Services Division, Epidemiology and Disease Control Unit. Innovative care for chronic conditions. February 2002

9 US Department of Health and Human Services. National healthcare disparities report. Rockville, MD: Agency for Healthcare Research and Quality (AHRQ), 2003.

10 Blendon RJ, Schoen C, DesRoches C, et al. Common concerns among diverse systems: health care experiences in five countries. Health Aff 2003;22:106-21.

11 Becher EC, Chassin MR. Improving the quality of health care: who will lead? Health Aff 2001;2:164-79.

12 Wang PS, Berglund P, Kessler RC. Recent care of common mental disorders in the United States: prevalence and conformance with evidence-based recommendations. J Gen Intern Med 2000;15:284-92.

13 Gulliford MC, Alert CV, Mahabir D, et al. Diabetes care in middle-income countries: a Caribbean case study. Diabet Med 1996;13:574-81.

14 Beattie A, Kalk WJ, Price M, et al. The management of diabetes at primary level in South Africa: the results of a facility-based assessment. $J R$ Soc Health 1998;118:338-45.

15 Raheja BS, Kapur A, Bhoraskar A, et al. DiabCare Asia-India study: diabetes care in India-current status. J Assoc Physicians India 2001;49:717-22.

16 Wagner EH, Davis C, Schaefer J, et al. A survey of leading chronic disease management programs: are they consistent with the literature? Manag Care $Q$ 1999;7:56-66.

17 Wagner EH, Austin BT, Davis C, et al. Improving chronic illness care: translating evidence into action. Health Aff 2001;20:64-78.

18 Bodenheimer T, Wagner EH, Grumbach K. Improving primary care for patients with chronic illness: the chronic care model, part 2. JAMA 2002;288:1909-14.

19 Bodenheimer T, Lorig K, Holman $\mathrm{H}$, et al. Patient self-management of chronic disease in primary care. JAMA 2002;288:2469-75.

20 Norris SL, Engelgau MM, Narayn KM. Effectiveness of self-management training in type 2 diabetes: a systematic review of randomized controlled trials. Diabetes Care 2001;24:561-87.

21 Guevara JP, Wolf FM, Grum CM, et al. Effects of educational interventions for self-management of asthma in children and adolescents: systematic review and meta-analysis. BMJ 2003;326:1308-9.

22 Clark NM. Management of chronic disease by patients. Annu Rev Public Health 2003;24:289-313.

23 Glasgow RE, Funnell MM, Bonomi ME, et al. Self-management aspects of the improving chronic illness care breakthrough series: implementation with diabetes and heart failure teams. Ann Behav Med 2002;27:80-7.

24 Norris SL, Lau J, Smith SJ, et al. Self-management education for adults with type 2 diabetes: a meta-analysis of the effect on glycemic control. Diabetes Care 2002;25: $1159-71$

25 Institute of Medicine. Crossing the quality chasm: a new health system for the 21 st century. Washington, DC: National Academy Press, 2001.

26 Wagner EH. The role of patient care teams in chronic disease management. BMJ 2000;320:569-72.

27 Anderson GF. Physician, public, and policymaker perspectives on chronic conditions. Arch Intern Med 2003;163:437-42.

28 Vladeck BC. You can't get there from here: obstacles to improving care of the chronically ill. Health Aff 2001;20:175-9.

29 World Health Organization. Innovative care for chronic conditions: building blocks for action. Geneva: World Health Organization, 2002.

30 Farmer P, Leandre F, Mukherjee JS, et al. Community-based approaches to HIV treatment in resource-poor settings. Lancet 2001;358:404-9.

31 Lorig K, Ritter P, Steward A, et al. Chronic disease self management programme: 2 year health status and health care utilization outcomes. Med Care 2003;39:1217-23.

32 Blendon RJ, Schoen C, Donelan K, et al. Physicians' views on quality of care: a five-country comparison. Health Aff 2001;20:233-43.

33 Nsutebu EF, Walley JD, Mataka E, et al. Scaling-up HIV/AIDS and TB homebased care: lessons from Zambia. Health Policy Plan 2001;16:240-7.

34 The Soul City Institute for Health and Development Communication. hitp:// www. soulcity.org.za (accessed 20 February 2004). 
35 Ministry of Finance, Government of India. http://indiabudget.nic.in/ es2001-02/welcome.html (accessed 20 February 2004).

36 Government of the Philippines. http://www.unescap.org/pop/database/ law_phi/phi_010.htm\#top (accessed 20 February 2004).

37 Abramson WB. Monitoring and evaluation of contracts for health service delivery in Costa Rica. Health Policy Plan 2001;16:404-11.

38 Coleman R, Gill G, Wilkinson D. Noncommunicable disease management in resource-poor settings: a primary care model from rural South Africa. Bull WHO 1998;76:633-40.

39 World Health Organization. http://www.who.int/tobacco/fctc/en/ (accessed 20 February 2004).

40 Yad Sarah. http://www.yadsarah.org.il/english/ laccessed 20 February 2004).
41 Barr VJ, Robinson S, Marin-Link B, et al. The expanded Chronic Care Model: an integration of concepts and strategies from population health promotion and the Chronic Care Model. Hosp Q 2003:7:73-82.

42 Leatherman S, Sutherland K. A quest for quality in the NHS: a mid-term evaluation of the 10-year quality agenda. UK: The Nuffield Trust, 2003.

43 Lewis R, Dixon J. Rethinking management of chronic diseases. BMJ 2004;328:220-2.

44 Epping-Jordan JE, Ludman EJ. Diffusion of innovations in health care (letter) JAMA 2003;290:1455-6.

45 Kravitz RL, Bell RA, Azari R, et al. Direct observation of requests for clinical services in office practice: what do patients want and do they get it? Arch Intern Med 2003;163:1673-81.

A unified approach to clinical testing in acute medical admissions may protect health resources

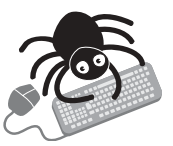

Please visit the Quality and Safety in Health Care website [www.qshc. com] for a link to the full text of this article. octors studying patient profile and organisational factors in relation to hospital stay in
Northern Ireland have concluded that a systematic approach to requesting clinical
investigations would help to conserve health resources. A median stay of seven days (interquartile range 3-12 days) for emergency admissions to a medical ward was significantly extended for patients who were elderly, managed in a medical word, or admitted on a Friday. Consultants' requests for chest $x$ ray examinations and echocardiography also lengthened median stay-from six to eight days; so did type of primary disease: tumours, congestive heart failure, stroke, and respiratory disease-from six to nine days or more. Taken together in a multivariate analysis, older age ( $\geqslant 75 v<63$ years) or having a tumour was over three times more likely to predict a stay of eight days or more, and having a respiratory condition over one and a half times more likely. Perhaps surprisingly, significant variation among consultants in ordering tests did not affect hospital stay. Nevertheless, unifying test requests still offers potential scope for saving resources, say the study's authors.

This study was a prospective observational study of emergency admissions to the medical ward of one Belfast teaching hospital over six months in 2000. Data were collected during post-take ward rounds after admission. The study covered 830 hospital stay episodes in patients (mean age 64.5 (SD18.0) years).

Whether demographic and organisational factors affect hospital stay has not been reported in the UK. Elsewhere their effect has been noted separately, but not together.

A Postgraduate Medical Journal 2004;80:23-26. 